\title{
Classification and Ordination of Seral Plant Communities
}

\author{
GARY HUSCHLE AND M. HIRONAKA
}

\begin{abstract}
A conceptual model of secondary succession was tested with data from disturbed vegetation in the $A$ gropyron/Poa habitat type using a combination of classification and ordination techniques. Individual stands were classified into communities by an agglomerative method. Results of the Bray-Curtis polar ordination using three endpoint selection methods supported the validity of the model. The model is visualized as a solid cone in which all of the plant communities included in a habitat type are positioned relative to their degree of disturbance, inferring their probably secondary successional pattern within habitat types.
\end{abstract}

Most of our nation's range vegetation is in some stage of secondary succession. One of the aims of modern resource management is to direct plant succession toward a desired seral stage in order to obtain maximum productivity or stability (Stoddart et al. 1975). Williams et al. (1969) point out that natural succession may be the most economical means, and in many inaccessible areas the only means, to restore the resource to a level of production that can be managed economically. In order to use secondary succession as a tool to attain this level, it is essential to have a better understanding of seral communities. Reviews on succession were made by Drury and Nisbet (1973) and Golley (1977).

Tree age data are widely used in study of forest succession (Botkin et al. 1972; Zedler and Goff 1973; Horn 1975). Because age of perennial herbs is not determinable, the same approach cannot be applied to study secondary succession of grassland vegetation. This paper deals with testing of a conceptual model of secondary succession in which age of plant is not involved.

The relatively recent availability of computer and multivariate analytical techniques adapted for vegetational analysis permit researchers to analyze and interpret large quantities of data. These techniques help reveal relationships of plant communities not previously possible. Reviews in use of multivariate techniques as applied to plant ecology have been published by Crovello (1970), Goodall (1970), Williams (1971), Orloci (1973), Clifford and Stephenson (1975), and others.

The purpose of this study was to test the validity and soundness of a conceptualized model of secondary succession that was developed recently. The model is visualized as a solid cone with the climax plant community situated at the

\footnotetext{
At the time of the research, authors were with the College of Forestry, Wildlife, and Range Sciences, University of Idaho, Moscow 83483. G. Huschlc's present address is U.S. Fish and Wildlife Service, Roy, Montana 59471.

The paper is published with the approval of the director, Forest, Wildlife, and Range Experiment Station, Univ. of Idaho, as Contribution No. 53.

This study was part of a United States Army Corps of Engineers contract with the Idaho Cooperative Wildlife Research Unit, College of Forestry, Wildlife and Range Sciences, University of Idaho Daa in this study were collected by personnel of the Idaho Cooperative Research Unit. Special thanks are extended to Dr. Duane Asherin, $\mathrm{Mr}$. James Claar and Mr. Jerry Lauer for their contributions to the study. Manuscript received December 15, 1978.
}

apex and associated seral communities positioned in their respective positions in the remaining portion of the cone.

The solid cone model may be illustrated by a habitat type, for example, which is defined as the collective area of land supporting or capable of supporting a specific climax plant community (Daubenmire 1970). Secondary succession within a habitat type is a continuum of plant communities whose endpoint is the climax vegetation. Within the habitat type there may be numerous plant communities in various stages of secondary succession. Conceptually, secondary succession can be viewed as a solid cone in which are contained all the plant communities associated with a single habitat type or having the same successional endpoint. The solid cone includes all of the disturbed communities within a habitat type, converging to the climax community that is positioned at the upper portion of the cone (Fig. 1). As succession returns toward climax, the vegetational compostion changes continuously until it reaches the climax association. Toward the base of the cone, numerous communities exist because different kinds and intensities of disturbance result in different vegetation. If the disturbance is severe enough, a community with a single pioneer species or finally the base level of the cone, bare ground, may result.

While secondary succession is a vegetational continuum, it is convenient to recognize community types and seral stages for practical management. A community type of one habitat type may have greater resemblance to a seral community of another habitat type than to one of its own. All community types are not unique to a habitat type. This is shown by the overlap of community types of two adjacent habitat types in Figure 1.

Secondary succession can be studied by investigating

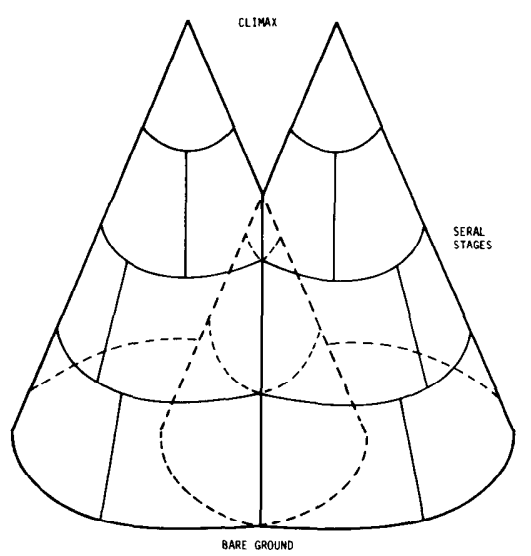

Fig. 1. Conceptual model of secondary succession in two closely associated habitat types. The overlap between cones represents plant communities common to both habitat types. 
plant communities resulting from disturbances that occurred at different times, provided that the communities are within the same habitat type. Natural field situations consist of stands that have been subjected to various kinds of disturbances occurring at different times and with different intensities. The problem is to determine the relative order of successional change among the seral communities that have the same successional end point.

\section{Study Area}

The study area included approximately 400 river miles of the middle and lower Snake River from West Lake Island near Weiser, Idaho, to its confluence with the Columbia River and downstream to McNary Dam. In many areas the upland grassland vegetation types extend down to the high water line.

The Columbia River basalt flows of Miocene times that covered the area to depths of $600 \mathrm{~m}$ (Cook 1954) are the most important geological feature of the study area. Between Idaho and Oregon, the Snake River has cut a deep gorge through a mountainous area known as Hells Canyon. In eastern Washington the river has cut through the Columbia River basalts leaving a deep canyon with many talus and steep upland slopes.

The Snake River Canyon has hot, dry summers and mild winters. The average annual air temperature is approximately $12^{\circ} \mathrm{C}$. The hottest temperatures are in July, with an average of approximately $24^{\circ} \mathrm{C}$. Minimum temperatures occur in January, with an average of $0^{\circ} \mathrm{C}$. Average annual precipitation rate varies from 18 $\mathrm{cm}$ at Kennewick, Washington, located at the west end of the study area, to $35 \mathrm{~cm}$ at Lewiston, Idaho (U.S. Bur. Reclam. 1972).

\section{Procedures}

\section{Sampling}

Data from 27 stands sampled in the Agropyron spicatum/Poa sandbergii habitat type (Daubenmire 1970) are used in this paper. Data collected consisted of a list of species and their frequencies of occurrence in $2 \times 5-\mathrm{dm}$ plots, and percent ground and basal cover of herbaceous species. Details of the sampling methods are presented in Huschle (1975). Analysis of presence-absence data included only those species that had frequency percentages of $10 \%$ or greater.

\section{Data Analyses}

Presence and absence data were used in a polythetic agglomerative technique to classify the vegetation into communities (recognizable aggregates of plant species within the vegetation types). The program used in this classification was Program MDISP, as presented by Goldstein and Grigal (1972). Orloci's (1967) method of the least increase in sums of squares is used in this program to unite stands. This method has produced good results in several other phytosociological studies (Edwards and Covalli-Sforza 1965; Allen 1971; Pyott 1972).

\section{Ordination}

The Bray and Curtis (1957) method with the index of similarity as presented in Program CEP4 of the Cornell Ecology Series of Computer Programs (Gauch and Dripps 1973) was used as the ordination technique in this study. The data were standardized by relativizing the scores in each stand to 100 to minimize the effect of differences in number of species between stand. Two sets of ordinations were used: one was based on 27 individual upland stands; the second set was based on the 15 communities that were derived from the 27 stands by the agglomerative classification procedure.

Three methods of reference point selection were compared. Cornell Program CEP5 (Gauch and Dripps 1973) was used to obtain a similarity matrix for selecting the reference points. The first method of selection was a subjective choice of points by the researcher, using different end-point pairs to see which set yields the most interpretable results (Gauch and Dripps 1973). Stands were selected that represented the extremes of the successional gradient being examined. A near-climax stand and a very low-sera stand were selected for the $x$-axis reference points. Two very different seral stands were selected for the $y$-axis points.

For the selection of reference stands for the $x$-axis by objective methods, we used both the procedure described by Beals (1960) and that described by Newsome and Dix (1968). Selection of reference stands for the $z$-axis for all ordinations followed the method prescribed by Newsome and Dix (1968).

\section{Results and Discussion}

The three methods of reference point selection already described were used to ordinate the 27 individual sites and the 15 communities defined by the classification of the 27 sites. Each of the six ordinations was illustrated in a threedimensional drawing for interpretation. The ordination of communities by Beal's reference point method is shown in Figure 2. Similar results were produced by the other five ordinations.

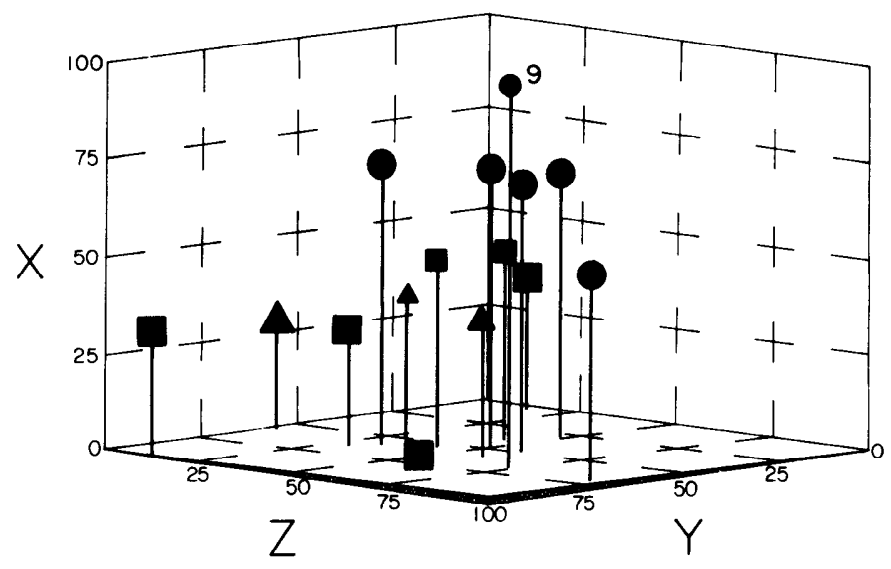

Fig. 2. Ordination of communities based on Beal's (1960) choice of reference points. Axes are oriented to position climax stands at the top of the drawing. The 15 communities represent three phases of the Agropyron/Poa habitat type. The triangles $(\Delta)$ represent sand dropseed phase communities; squares ( $\square)$ represent cheatgrass brome phase communities; circles (o) represent communities of the Japanese brome phase. Large symbols represent the lowest seral stages; medium-sized symbols represent seral stages nearer to climax; small symbols represent climax or near-climax communities. Stand 9 refers to the "climax" stand discussed in the paper.

Three phases of the Agropyron/Poa habitat type occur in the study area. One phase is characterized by the presence of sand dropseed (Sporobolus cryptandrus), which is indicative of sandy alluvial soils. This phase is found primarily on alluvial soils between Hells Canyon Dam and Wawawai, Washington (Daubenmire 1970). Sand dropseed is considered to be a member of its own climax plant association of the Sporobolus cryptandrus/Poa sandbergii habitat type on very sandy soils. It is also considered to be a long-lasting seral species of the Agropyron/Poa habitat type on more loamy soils (Daubenmire 1970). The presence of abundant Sandberg bluegrass (Poa sandbergii) and remnant bunches of bluebunch wheatgrass (Agropyron spicatum) indicates that the stand is of the Agropyron/Poa habitat type even though sand dropseed is present. ${ }^{1}$ All of the sand dropseed stands in this study except two had Sandberg bluegrass present, and it was readily apparent in the field that these two sites had been subjected to heavy concentrations of

'Personal communication with Dr. E.W. Tisdale, College of Forestry, Wildlife and Range Sciences, University of Idaho, Moscow. 
livestock. Several of the other sites had bluebunch wheatgrass present. All of the sites occupied similar level benches above the river. For these reasons, the sand dropseed stands sampled in this study were considered to be seral stages of the Agropyron/Poa habitat-type.

A second phase is associated with the dry alluvial soils characteristic of the Snake River Canyon in Washington. The seral vegetation in this area is predominatly cheatgrass brome (Bromus tectorum) and it is therefore referred to as the cheatgrass brome phase.

A third phase occurs on the residual soils in the steeper parts of the Snake River canyon between Idaho and Oregon. The more mesic brome species such as rattlesnake brome (Bromus brizaeformis), Japanese brome (Bromus japonicus), and soft brome (Bromus mollis) occur here in addition to cheatgrass brome. The most abundant and widespread of the mesic bromes, Japanese brome, is used as the name of this phase.

The successional sequence in each of the three phases should be fairly distinct within the overall Agropyron/Poa succession. In order to test this, the identity of each of the three phases was maintained in the three-dimensional drawings illustrating the results of the ordinations by indicating each phase with a different symbol (Fig. 2). In all three phases the stands were categorized as low-seral (large symbols), seral (medium symbols), or climax (small symbols) on the basis of their species composition and relationships brought out by the classification. Stand 9 was considered to be the best example of Agropyron/Poa climax and is the only stand represented by a small symbol.

In comparing the ordination in Figure 2 to the cone model, it is easy to see the wide seral base across the bottom of the drawing. The large symbols are the lowest in the drawing. The medium symbols are above the large ones and the small circle is located near the top. The ordination narrows to a peak at stand 9, the "climax" stand. The three types of figures representing the successional sequence for each of the three phases are fairly well grouped.

The successional pathway from any point within the cone is upward. Over time a community would tend to change and resemble a community nearer to the endpoint as secondary succession proceeds unhindered. Realistically, the pathway would probably be a series of short deflected paths due to variations in weather, seed availability and minor disturbances.

A catastrophic disturbance, natural (drought, fire) or man-caused, would drastically alter a plant community and result in a community disjunct in position from its location in the cone prior to disturbance. The resulting community would then be the initial point for a new sequence in secondary succession. Its new position in the cone would be further removed from the endpoint. At times, however, a community may be displaced laterally or even nearer the endpoint if a seral species was selectively and abruptly removed from a community.

Presence or absence of species proved to be an adequate criterion for classifying plant communities and is in agreement with the findings of Smartt et al. (1976). The ordinated presence and absence data also gave satisfactory results in displaying successional relationships. For most purposes the utility of a finer breakdown produced by the use of quantitative data would be unnecessary. A classification based solely on the presence or absence of the important species is much easier and more practical for land manage- ment purposes and probably is adequate for many vegetational studies.

The classification process used in this study does not segregate the stand members of one habitat type from members of another habitat type. This is because the seral stands from two habitat types may be more similar to each other than to other stands in their respective habitat types. An objective means of separating seral sites into their respective habitat types is still needed.

Ordination is a valuable tool for looking at secondary succession. Ordination not only displays the basic successional trends but also shows the different phase sequences in multidimensional space. The objective procedures for selecting reference points resulted in the same basic successional trends that were obtained by selecting reference points subjectively. The greatest difference, displayed by the first $(x)$ axis, is between the site representing climax and the lowest seral site. This confirms the fact that secondary successional gradients are represented by the major axes in the ordination of an array of seral sites.

Ordination at the community type level produced the same results as ordination at the stand level. As the number of stands increases, there comes a point where stand ordination becomes cluttered and difficult to interpret. Classifying the stands into community types and then ordinating produce a clear and still accurate picture when many stands are involved.

The cone model is still a simplification of the real world. The real environment may distort or never produce some parts of the cone. This study has shown the model to be useful for conceptualizing changes that take place in secondary succession.

The objective procedures used in this study are only a few of the many techniques and combinations of techniques that have been developed for this type of analysis and may not meet the specific needs of some researchers. They are, however, readily available and fairly simple, and produced interpretable results in this study. Some subjectivity, based on the ecologist's interpretations, must be maintained in order to fully evaluate and correct faults inherent in the artificiality of the objective methods.

\section{Literature Cited}

Allen, T.F.H. 1971. Multivariate approaches to the ecology of algae on terrestrial rock surfaces in N. Wales. J. Ecol. 59: 803-826

Beals, E.W. 1960. Forest bird communities in the Apostle Islands of Wisconsin. Wilson Bull. 72: 156-181.

Botkin, D.B., J.F. Janak, and J.R. Wallis. 1972. Some ecological consequences of a computer model of forest growth. J. Ecol. 60:849-872.

Bray, J.K., and J.T. Curtis. 1957. An ordination of the upland forest communities of southern Wisconsin. Ecol. Monogr. 27: 325-349.

Cook, E.F. 1954. Mining geology of the Seven Devils region. Idaho Bureau of Mines and Geology Pam. No. 97. Moscow, Idaho. 22 p.

Crovello, T.J. 1970. Analysis of character variation in ecology and systematics. Annu. Rev. Ecol. Syst. 1: 55-98.

Daubenmire, R. 1970. Steppe vegetation of Washington. Washington Agricultural Experiment Station Tech. Bull. 62. College of Agriculture, Washington State Univ., Pullman. 131 p.

Drury, W.H., and I.C.T. Nisbet. 1973. Succession. J. Arnold Arbor 54:331-368.

Edwards, A.W.F., and L.L. Covalli-Sforza. 1965. A method for cluster analysis. Biometrics 21: 362-375.

Gauch, H.G. Jr., and B.A. Dripps. 1973. Cornell ecology program series, 4th edition. Department of Fcology and Systematics, Cornell Univ. Ithaca, New York.

Goldstein, R.A., and D.F. Grigal. 1972. Computer programs for the ordination and classification of ecosystems. Ecological Sciences Division Pub. No. 417. ORNL-IBP-71-10. Oak Ridge National Laboratory, Oak 
Ridge, Tennessee. $125 \mathrm{p}$

Golley, F.B. (ed.). 1977. Ecological Succession. Benchmark Papers in Ecology. Dowden, Hutchinson and Ross, Inc., Stroudburg, Penn. 373 p. Goodall, D.W. 1970. Statistical plant écology. Annu. Rev. Ecol. Syst. 1:99124.

Horn, H.S. 1975. Markovian properties of forest succession. In: Ecology and Evolution of Communities. (Ed.) Martin L. Cody and Jared M. Cody.

Belknap Press of Harvard Univ. Press. Cambridge, Mass.

Huschle, G. 1975. Analysis of the vegetation along the middle and lower Snake River, M.S. Thesis. Univ. Idaho, Moscow. 271 p.

Newsome, R.D., and R.L. Dix. 1968. The forests of the Cypress Hills, Alberta and Saskatchewan, Canada. Amer. Midl. Natur. 80: 118-185.

Orloci, L. 1967. An agglomerative method for classification of plant communities. J. Ecol. 55: 193-206.

Orloci L. 1975. Multivariate Analysis in Vegetation Research. Junk, The Hague.
Pyott, W.T. 1972. Numerical classification of range vegetation and statistical analysis of its ecology. Ph.D. Diss. Oregon State Univ., Corvallis.

Smartt, P.F.M., S.E. Meacock, and J.M. Lambert. 1976. Investigations into the properties of quantitative vegetational data. II. Further data type comparisons. J. Ecol. 64: 41-78.

Stoddart, L.A., A.D. Smith, and T.W. Box. 1975. Range Management, 3rd edition. McGraw-Hill, Inc., New York. 532 p.

U.S. Bureau of Reclamation. 1972. Lower Snake River Basin-IdahoWashington. Basin Survey. 86 p.

Williams, W.T. 1971. Principles of clustering. Annu. Rev. Ecol. Syst. 2: 303-326.

Williams, W.T., G.N. Lance, L.J. Webb, J.G. Tracey, and M.B. Dale. 1969. Studies in the numerical analysis of complex rain-forest communities. $\mathbf{J}$. Ecol. 57: 515-535.

Zedler, P.H., and F.G. Goff. 1973. Size-association analysis of forest successional trends in Wisconsin. Ecol. Monogr. 43: 79-94. 